UDC 576

BBC 28.05

\title{
THE PHENOMENON OF HYPERCELLULARITY IN OSTEOARTHRITIS AND MODIFICATION OF SYNOVIAL FLUID
}

\author{
Ekaterina A. Bliznyukova \\ Volgograd State University, Volgograd, Russian Federation \\ Pavel A. Krylov \\ Volgograd State University, Volgograd, Russian Federation
}

\begin{abstract}
Articular cartilage is a thin layer of connective tissue that consists of tissue fluid and structural macromolecules, including collagens, proteoglycans, non-collagen proteins and glycoproteins without blood vessels, nerves or lymph nodes. It has a limited ability to self-healing. In addition, chondrocytes, which are surrounded by an extracellular matrix, cannot freely migrate to the site of damage from a healthy place, unlike most tissues. Because of this, even a small defect in the articular cartilage caused by mechanical damage can lead to a disease such as osteoarthritis. The task associated with the restoration of articular cartilage is complex, since conventional imaging methods can detect only progressive forms of osteoarthritis. Hypercellularity is one of the stages of the main processes occurring in osteoarthritis. At its early stages, hypercellularity has a remodeling, that is, restorative effect, but subsequently it goes into the stage of degradation, that is, a pathological process is observed. The problem of the transition of hypercellularity from a "restorative" to a "pathological" process, which is irreversible, has been poorly studied. This paperconsiders the aspects that could affect hypercellularity. The main goal of the work is to study the phenomenon of hypercellularity and proliferative activity of chondrocytes in the articular cartilage. The authors identifythe symptoms and causes of osteoarthritis, its stages and study the structural composition of the articular cartilage in order to consider the proliferative activity of chondrocytes in it. The paper investigates and analyzes thephenomenon of hypercellularity.
\end{abstract}

Key words: osteoarthrosis (osteoarthritis), hypercellularity, articular cartilage, chondrocytes, synovial fluid.

УДК 576

ББК 28.05

\section{ФЕНОМЕН ГИПЕРКЛЕТОЧНОСТИ ПРИ ОСТЕОАРТРОЗЕ И МОДИФИКАЦИИ СИНОВИАЛЬНОЙ ЖИДКОСТИ}

\author{
Екатерина Александровна Близнюкова \\ Волгоградский государственный университет, г. Волгоград, Российская Федерация \\ Павел Андреевич Крылов \\ Волгоградский государственный университет, г. Волгоград, Российская Федерация
}

\begin{abstract}
Аннотация. Суставной хрящ представляет собой тонкий слой соединительной ткани, который состоит из тканевой жидкости и структурных макромолекул, включая коллагены, протеогликаны, неколлагеновые белки и гликопротеины без кровеносных сосудов, нервов или лимфатических узлов. Он обладает ограниченной способностью к самовосстановлению. Кроме того, хондроциты, которые окружены внеклеточным матриксом, не могут свободно мигрировать в место повреждения из здорового места, в отличие от большинства тканей. Из-за этого даже небольшой дефект в суставном хряще, вызванный механическим повреждением, способен привести к такому заболеванию, как остеоартроз. Задача, связанная с восстановлением суставного хряща сложная, так как обычные методы визуализации способны обнаруживать только прогрессирующие формы остеоартроза. Гиперклеточность является одной из стадий основных процессов происходящих при остеоартрозе. Гиперклеточность на ранних своих этапах имеет ремоделирующее, то есть восстановительное
\end{abstract}


действие, но впоследствии она переходит в стадию деградации, то есть наблюдается патологический процесс. Проблема перехода гиперклеточности из «восстановительного» в «патологический» процесс, имеющий необратимый характер, является малоизученным. В данной работе рассматривались аспекты способные повлиять на гиперклеточность. Основной целью работы является изучение феномена гиперклеточности и пролиферативной активности хондроцитов в суставном хряще. По мере изучения данной темы были выявлены симптоматика и причины возникновения остеоартроза, его этапы. Изучена структура строения суставного хряща, с целью рассмотрения в нем пролиферативной активности хондроцитов. Исследован и проанализирован феномен гиперклеточности.

Ключевые слова: остеоартроз, гиперклеточность, суставной хрящ, хондроциты, синовиальная жидкость.

Введение. Остеоартроз - это дегенеративное заболевание суставов, которое серьезно влияет на качество жизни. Традиционные методы лечения лишь временно ослабляют клинические симптомы, но не эффективно подавляют патологическое развитие заболевания. Поэтому важно выяснить механизмы, ответственные за него, и определить безопасные и эффективные методы его лечения. Обычно симптомы прогрессируют медленно в течение многих лет и способны мешать нормальной повседневной деятельности [15;28].

В первую очередь происходит повреждение синовиальной оболочки, которая покрывает концы костей в суставе, что создает условие для трения между костями. Причины могут включать в себя предыдущую травму сустава, неправильное развитие суставов или конечностей и наследственные факторы. Считается, что остеоартроз вызван механической нагрузкой на сустав и в слабой степени воспалительным процессом [21; 27; 32].

При остеоартрозе могут быть распознаны разные фазы, которые не только различаются по времени, но могут происходить одновременно в суставе, но в разных местах:

1. Стадия инициации - это начальная стадия, которая является наименее изученной, так как выявить заболевание на первых этапах очень сложно, а при попытке изучения сустава на данной стадии есть риск увеличить процесс прогресса остеоартроза.

2. Стадия прогрессии - основные «визуальные» отличия факторы, высвобождаемые из поврежденного хрящевого матрикса и активированных синовиальных клеток, будут привлекать воспалительные клетки, такие как макрофаги, и стимулировать синовиальный фиброз. Кроме того, повышенные уровни TGFв будут вызывать образование остеофитов, происходящих из клеток мезенхимных пред- шественников в надкостнице. Это ранняя стадия, которая не будут диагностироваться как клинический остеоартроз.

3. Поздняя стадия. Хрящ содержит участки, которые сильно повреждены. Хрящ рядом с поврежденными участками содержит популяцию хондроцитов, которая, по-видимому, участвует в попытке исправить повреждение. Эти клетки, которые показывают признаки пролиферации клеток, расположены в кластерах и показывают высокие уровни фосфорилирования. Эти клетки, хотя и участвуют в попытке восстановления, вероятно, способствуют дальнейшему повреждению хряща своими активированными характеристиками, примером чего является повышенная продукция ММР13. Похоже, что эта популяция «репаративных» клеток присутствует только в сильно поврежденных областях, так как более интактный человеческий хрящ не показывает эти кластеры клеток.

4. Конечная стадия. Конечная стадия будет представлять собой сильно поврежденный хрящ с трещинами и трещинами менее поврежденного фибриллированного хряща и хряща, который выглядит гистологически относительно нормальным. В сильно поврежденном хряще обнаружены кластеры хондроцитов. На краях суставов присутствуют кальцинированные остеофиты и синовиальная ткань активируется, показывая воспалительные клетки, пролиферацию клеток и фиброз $[4 ; 25]$.

Суставной хрящ. Суставной хрящ на 65-80 \% из тканевой жидкости, коллагена типа II и протеогликанов. Такое высокое содержание жидкости позволяет питательным веществам и кислороду диффундировать через хрящевую матрицу к его клеткам. Коллаген типа II составляет 15-22 \%, а протеогликаны 4-7 \% от общей массы хряща. Другие колла- 
гены и протеогликаны, такие как коллагены типов V, VI, IX, X, XI, XII, XIV и декорин, бигликан, фибромодулин, люмикан, эпификан и перлекан составляют небольшую часть, менее $5 \%$, от нормальной массы хряща $[10 ; 20]$.

Матрица коллагена и протеогликана обеспечивает суставной хрящ растяжимой и упругой прочностью, которая позволяет суставам поддерживать надлежащую биомеханическую функцию. По мере созревания суставного хряща хондроциты поддерживают хрящ, синтезируя компоненты матрикса и его ферменты с минимальным расходом клеток и матрикса. Существующая коллагеновая сеть становится сшитой, и суставной хрящ созревает в постоянную ткань со способностью поглощать и реагировать на механическое напряжение [20; 26; 31].

Основная функция суставного хряща обеспечить гладкую смазанную поверхность для сочленения и облегчить нагрузку. Суставной хрящ не имеет кровеносных сосудов, нервных окончаний и лимфатических узлов, но обладает локальной способностью к репаративной регенерации. Выделяют три вида хряща, которые распределены во многих областях скелета, особенно в суставах и где необходима гибкая поддержка:

1. Эластичный хрящ - это такой вид хряща, который обеспечивает прочность и эластичность. Клетки в нем расположены близко друг к другу, создавая лишь небольшое межклеточное пространство.

2. Волокнистый хрящ состоит в разных пропорциях из хрящевой и фиброзной ткани. Он имеет наименьшее количество клеток, в отличие от эластичного и гиалинового хряща, за счет этого, у него больше межклеточного пространства.

3. Гиалиновый хрящ. Клеток в гиалиновом хряще меньше, межклеточное пространство больше, чем в эластичном хряще.

Хондроциты. Хондроциты присутствуют в поверхностной, средней, глубокой и кальцинированной зоне суставного хряща [14; $16 ; 30]$.

Поверхностная зона защищает зоны расположенные глубже от давления, оказанного на сустав. Она содержит большое количество овальных хондроцитов и составляет 10-20\% от всей толщины суставного хряща. Коллаге- новые волокна этой зоны плотно упакованы и выровнены параллельно суставной поверхности. Эта зона находится в непосредственном контакте с синовиальной жидкостью и позволяет хрящу противостоять действию различных сил, создаваемых суставами [7; 13].

Средняя зона обеспечивает анатомическую и функциональную связь между поверхностной и глубокой зонами. Она состоит из сферических хондроцитов с низкой плотностью и составляет 40-60\% от общего объема суставного хряща. Коллагеновые волокна организованы диагонально под наклоном. Эта зона выполняет функцию сопротивления силам сжатия [29].

Глубокая зона отвечает за обеспечение наибольшего сопротивления сжимающим силам. Она состоит из хондроцитов, которые располагаются в столбчатой ориентации, параллельно волокнам коллагена и перпендикулярно линии сустава и составляет примерно $30 \%$ от общего объема суставного хряща. Коллагеновые волокна в этой зоне наибольшего диаметра, в сравнении с поверхностной и средней зоной. Глубока зона имеет самое высокое содержание протеогликана и самую низкую концентрацию воды [5].

Кальцинированный слой играет важную роль в прикреплении хряща к кости за счет прикрепления коллагеновых волокон, которые расположены в глубокой зоне к субхондральной кости. В этой зоне популяция клеток недостаточна, а хондроциты гипертрофированы $[17 ; 18]$.

Хондроциты - это метаболически активные клетки, происходящие из мезенхимальных стволовых клеток и играющие уникальную роль в развитии, поддержании и восстановлении внеклеточного матрикса. Их классифицируют по форме, количеству и размеру в зависимости от анатомических областей суставного хряща. Хондроциты обладают ограниченным потенциалом для репликации. Репликация - это фактор, который способствует ограниченной внутренней способности заживления хряща в ответ на повреждение. Выживание хондроцитов зависит от оптимальной химической и механической среды $[13 ; 22 ; 27]$.

Хондроцит создает специализированную микросреду, которая позволяет фиксироваться ему в его собственной матрице. Такое вза- 
имодействие позволяет предотвратить любую миграцию в соседние области хряща. Редко хондроциты образуют межклеточные контакты для прямой передачи сигнала между клетками. Однако они реагируют на различные стимулы, включая факторы роста, механические нагрузки и гидростатические давления [12; 27; 31].

Синовиальная жидкость. Синовиальная жидкость представляет собой вязкую жидкость, обнаруживаемую в полостях суставов. Основная роль синовиальной жидкости заключается в уменьшении коэффициента трения скольжения между хрящом и суставов во время движения. Синовиальная жидкость представляет собой небольшой компонент межклеточной жидкости, компонент внеклеточной жидкости.

Основные характеристики синовиальной жидкости являются:

1. Она является диализатом плазмы крови, то есть той частью плазмы, которая прошла через мембрану, но она содержит большее количество гиалуроновая кислота, чем другие плазменные диализаты.

2. Она является тиксотропной жидкостью, то есть вязкой и эластичной. Ее вязкость уменьшается с увеличением скорости жидкости, когда она находится в движении. Ее эластичность, с другой стороны, увеличивается с увеличением скорости жидкости. Ее тиксотропия происходит из-за гиалуроновой кислоты в ней.

3. Функционально она выполняет две функции: питание и смазка. Было установлено, что только синовиальная жидкость, будучи диализатом плазмы крови, может питать части суставных хрящей. Его тиксотропные свойства делают его пригодным для формирования так называемых эластогидродинамических смазочных пленок между подвижной и неподвижной поверхностями любой сопряженной пары [1;24;30].

Пролиферация хондроцитов и гиперклеточность. Стандартный путь дифференцировки хондроцитов - это терминальная дифференцировка, включающая гипертрофия (гиперклеточность) и апоптоз. Гиперклеточность суставного хряща предполагает клеточную пролиферацию менее дифференцированных клеток. Моделью дифференцировки хон- дроцитов у взрослых является образование остеофитов. Остеофиты являются результатом хондрогенной дифференцировки мезенхимальных стволовых клеток в надкостнице. Конечной стадией гиперклеточности хондроцитов является отложение кальция. Кальцификация суставного хряща, по-видимому, связана с повышенной экспрессией маркеров гиперклеточности [6].

Апоптоз может рассматриваться как маркер гиперклеточности хондроцитов в хряще при остеоартрозе. Процесс, связанный с апоптозом является аутофагией. Аутофагия была выдвинута в качестве альтернативной причины гибели клеток хондроцитов при остеоартрозе. Или, напротив, аутофагия может быть механизмом защиты хряща, который теряется при старении и развитии остеоартроза [25]. Аутофагия регулируется рядом генов, связанных с ней, таких как BECN1 и LC3. Уровни экспрессии этих генов обычно используются для мониторинга активности аутофагии и ее потока. При исследовании влияния аутофагии на процесс остеоартроза, было выявлено, что аутофагия сначала резко усиливается, а затем ослабевает в клетках с коллаген-индуцированным остеоартрозом дегенеративного хряща. Предполагается, что регуляция процесса аутофагии может быть одной их потенциальных терапевтических стратегий для лечения заболевания [8;9].

Анализируя статьи по изучению остеоартроза, следует отметить, что в основном, для градации степени тяжести заболевания используют шкалу Мэнкина-Мартина и выделяют такие стадии, как:

1. Гладкая неповрежденная поверхность; равномерное распределение хондроцитов с одной или двумя клетками (лакуной).

2. Легкая фибрилляция поверхности; расщелины, не выходящие за пределы поверхностной зоны; небольшая гиперклеточность.

3. Различимы области утолщения или истончения хряща; глубокая фибрилляция; расщелины простираются в середину и иногда в кальцинированные зоны; гиперклеточность обычно в виде кластеров хондроцитов (клонов).

4. Области с полной толщиной разрушенного хряща; расщелины распространяются вниз на кальцинированный хрящ; гиперклеточ- 
ность; выраженная редупликация и сосудистая инвазия; наличие крупных остеофитов с костными пространствами $[2 ; 3 ; 19]$.

Остеоартроз неблагоприятно воздействует на несколько компонентов сустава, включая околосуставную ткань кости, синовиальную оболочку сустава и прилегающие элементы соединительной ткани (см. рисунок). Характерные структурные изменения при остеоартрозе включают прогрессирующую потерю суставного хряща, увеличение толщины субхондральной кости, образование новой кости на краях сустава, за счет появления остеофитов и развитие кист субхондральной кости. Кроме того, в месте соединения суставного гиалинового хряща и прилегающей субхондральной кости имеется остаток кальцинированного хряща. По мере прогрессирования остеоартроза имеются данные о сосудистой инвазии и расширения зоны кальцинированного хряща, что дополнительно способствует уменьшению толщины суставного хряща. Эти структурные изменения в суставном хряще и околосуставной кости могут привести к изменению контуров соседних суставных поверхностей [11; 23; 32].

Заключение. Хондроциты являются единственным типом клеток, которые составляют структуру хряща. Они производят и поддерживают хрящевой матрикс. Увеличение числа пролиферирующих клеток - является указателем восстановительного процесса происходящего в суставном хряще. В свою очередь, для поддер- жания популяции хондроцитов ключевое значение имеет их дифференцировка.

Гиперклеточность суставного хряща предполагает клеточную пролиферацию менее дифференцированных клеток. Ее конечной стадией является отложение кальция. Кальцификация суставного хряща связана с повышенной экспрессией маркеров гиперклеточности.

Исходя из проанализированных источников, можно сделать вывод, что процесс гиперклеточности не изучен до конца, так как до сих пор нет сведений о моменте, когда ее можно рассматривать, как патологию, а когда она является физиологической регенерацией суставного хряща, с использованием пролиферации и дифференцировки хондроцитов.

\section{СПИСОК ЛИТЕРАТУРЫ}

1. Морфология суставного хряща при экспериментальном остеоартрозе при коррекции состава синовиальной жидкости сурфактант-ассоциированными белками / П. А. Крылов [и др.] // Клиническая и экспериментальная морфология. - 2017. T. 3, № 23. - C. 50-55.

2. Морфология тибиофеморального сустава крысы при экспериментальном остеоартрозе: 3D-реконструкция на основе техники высокоточного сошлифовывания / П. А. Крылов [и др.] // Журнал анатомии и гистопатологии. - 2017. T. 6, № 3-C. 44- 49 .

3. Оценка эффективности лубриканта на основе легочного сурфактанта при эксперименталь-
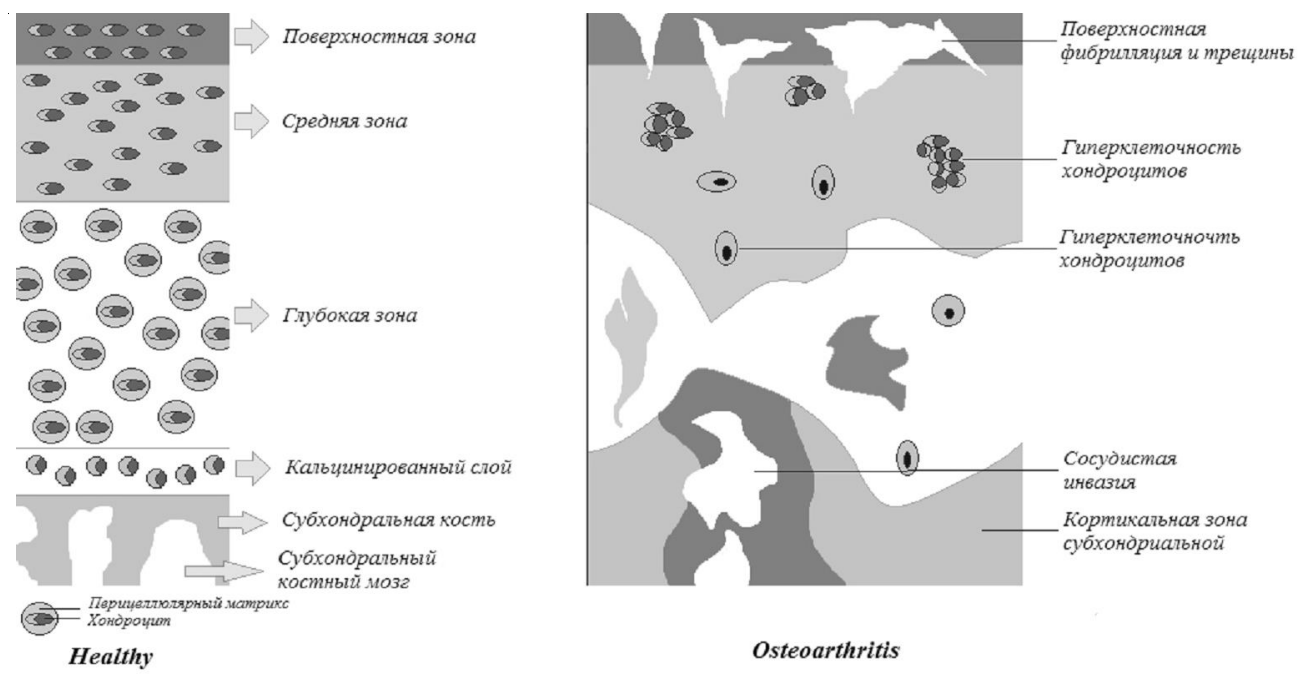

Структурные изменения при развитии остеоартроза 
ном остеоартрозе коленного сустава у крыс: анализ 3D-реконструкций / П. А. Крылов [и др.] // Бюллетень экспериментальной биологии и медицины. 2019. - № 168 (9). - C. 343-346.

4. Analysis of the Mineral Composition of the Human Calcified Cartilage Zone / Y. Zhang [et al.] // Internet Journal of Medical Sciences. - 2012. - Vol. 9, № 5. - P. 353-360.

5. Applications of Chondrocyte-Based Cartilage Engineering: An Overview / A.-R. Phull [et al.] // BioMed Research International. - 2016. № 1879837. -P. 17.

6. Articular Cartilage / A. Athanasiou [et al.]. $2^{\text {nd }}$ ed. - Boca Raton : CRC Press, 2017. -696 p.

7. Articular Cartilage: from Formation to Tissue Engineering / S. Camarero-Espinosa [et al.] // Biomaterials Science. - 2016. - Vol. 4, № 5. -P. 734-767. DOI: https://doi.org/10.1039/c6bm00068a.

8. Autophagy in Osteoarthritis / Y. S. Li [et al.]/ / Joint Bone Spine Volume. - 2016. - Vol. 83, № 2. P. 143-148. DOI: https://doi.org/0.1080/ 03008207.2016.1240790.

9. Cheng N-T. Role of Autophagy in the Progression of Osteoarthritis: The Autophagy Inhibitor, 3-Methyladenine, Aggravates the Severity of Experimental Osteoarthritis / N-T. Cheng, H. Meng, L-F. Ma // International Journal of Molecular Medicine - 2017. - Vol. 39, № 5. - P. 1224-1232. DOI: https://doi.org/10.3892/ijmm.2017.2934.

10. Comparison of Apoptosis and Autophagy in Human Chondrocytes Induced by the T-2 and HT-2 Toxins / F.-F. Yu [et al.] // Toxins (Basel). - 2019. Vol. 11, № 5. - P. 260. DOI: https://doi.org/10.3390/ toxins 11050260 .

11. Emmanuel, L. Animal Models of Osteoarthritis: Classification, Update, and Measurement of Outcomes / L. Emmanuel, N. Ganesh, S. Lakshmi // Journal of Orthopaedic Surgery and Research. - 2016. - Vol. 11. P. 19. DOI: https://doi.org/10.1186/s13018-016-0346-5.

12. Hwang, H. Chondrocyte Apoptosis in the Pathogenesis of Osteoarthritis / H. Hwang, H. Kim // International Journal of Molecular Sciences. - 2015. Vol. 16, № 11. - P. 26035-26054. DOI: https://doi.org/ 10.3390/ijms161125943.

13. Insights on Molecular Mechanisms of Chondrocytes Death in Osteoarthritis / E. Charlier [et al.] // International Journal of Molecular Sciences. 2016. - Vol. 17, № 12. - P. E2146. DOI: https://doi.org/ 10.3390/ijms17122146.

14. Jahn, S. Lubrication of Articular Cartilage / S. Jahn, J. Seror, J. Klein// Annual Review of Biomedical Engineering - 2016 - Vol. 18, № 1. - P. 235-258. DOI: https://doi.org/10.1146/annurev-bioeng-081514-123305.

15. Johnson, V. L. The Epidemiology of Osteoarthritis / V. L. Johnson, D. J. Hunter // Best Practice \& Research Clinical Rheumatology. - 2014. -
Vol. 28, № 1. - P. 5-15. DOI: https://doi.org/10.1016/ j.berh.2014.01.004.

16. Kraan, P. M. Chondrocyte Hypertrophy and Osteoarthritis: Role in Initiation and Progression of Cartilage Degeneration? / P. M. Kraan, W. B. Berg // Osteoarthritis and Cartilage. - 2012. - Vol. 20, № 3. P. 223-232.1. DOI: https://doi.org/10.1016/ j.joca.2011.12.003.

17. Krylov, P. A. The Grouping of Chondrocyte Receptors According to Their Control Over Cartilage Tissue Remodeling / P. A. Krylov // European Journal of Molecular Biotechnology. - 2014. - Vol. 1, № 3. P. 4-10. DOI: https://doi.org/10.13187/ejmb.2014.3.4.

18. Loeser, R. F. Ageing and the Pathogenesis of Osteoarthritis / R. F. Loeser, J. A. Collins, B. O. Diekman // Nature Reviews Rheumatology. - 2016. - Vol. 12, № 7. - P. 412-420. DOI: https://doi.org/10.1038/ nrrheum.2016.65.

19. McCulloch K. Cellular Senescence in Osteoarthritis Pathology/ K. McCulloch, G. J. Litherland, T. S. Rai// Aging Cell. -2017. - Vol. 16, №2. - P. 210-218. DOI: https://doi.org/10.1111/acel.12562.

20. Osteoarthritis / S. Glyn-Jones [et al.] // The Lancet. - 2015. - Vol. 386, № 9991. - P. 376-387. DOI: https://doi.org/10.1016/S0140-6736(14)60802-3.

21. Osteoarthritis and Mortality: a Prospective Cohort Study and Systematic Review with Metaanalysis / N. Veronese [et al.] // Seminars in Arthritis and Rheumatism. - 2016. - Vol. 46, № 2. - P. 160-167. DOI: https://doi.org/10.1016/j.semarthrit.2016.04.002.

22. Osteoarthritis as a Disease of the Cartilage Pericellular Matrix / F. Guilak [et al.] // Matrix biology: Journal of the International Society for Matrix Biology. -2018. - Vol. 71-72. - P. 40-50. DOI: https:// doi.org/10.1016/j.matbio.2018.05.008.

23. Osteoarthritis Cartilage Histopathology: Grading and Staging / K. Pritzker [et al.] // Osteoarthritis Research Society International. - 2006. - Vol. 14, № 1. P. 13-29. DOI: https://doi.org/10.1016/j.joca.2005.07.014.

24. Osteoarthritis Pathogenesis: A Review of Molecular Mechanisms / B. Xia [et al.] // Calcified Tissue International. - 2014. - Vol. 95, № 6. - P. 495505. DOI: https://doi.org/10.1007/s00223-014-9917-9.

25. Osteoarthritis: Toward a Comprehensive Understanding of Pathological Mechanism / D. Chen [et al.] // Bone Research. - 2017. - Vol. 5, № 16044. DOI: https://doi.org/10.1038/boneres.2016.44.

26. Rebekah, S. Articular Cartilage and Joint Development from Embryogenesis to Adulthood / S. Rebekah // Seminars in Cell \& Developmental Biology. - 2017. - Vol. 62. - P. 50-56. DOI: https:// doi.org/10.1016/j.semcdb.2016.10.005.

27. Risk Factors and Burden of Osteoarthritis / C. Palazzo [et al.] // Annals of Physical and Rehabilitation Medicine. - 2016. - Vol. 59, №3. - P. 134 138. DOI: https://doi.org/10.1016/j.rehab.2016.01.006. 
28. Sellam, J. Is Osteoarthritis a Metabolic Disease? / J. Sellam, F. Berenbaum // Joint Bone Spine. 2013. - Vol. 80, № 6. - P. 568-573. DOI: https://doi.org/ 10.1016/j.jbspin.2013.09.007.

29. Simon, T. M. Articular Cartilage: Injury Pathways and Treatment Options / T. M. Simon, D. W. Jackson // Sports Medicine and Arthroscopy Review. - 2018. - Vol. 26, № 1.- P. 31-39. DOI: https:/ /doi.org/10.1097/JSA.0000000000000182.

30. Synovial Fluid Mononuclear Cells Provide an Environment for Long-Term Survival of AntibodySecreting Cells and Promote the Spontaneous Production of Anti-Citrullinated Protein Antibodies / P. F. Kerkman [et al.] // Annals of the Rheumatic Diseases. - 2016. - Vol. 75, № 12. - P. 2201-2207. DOI: https://doi.org/10.1136/annrheumdis-2015-208554.

31. Synovial Joints: Mechanobiology and Tissue Engineering of Articular Cartilage and Synovial Fluid / A. R. Raleigh [et al.] // Comprehensive Biomaterials II. - 2017. - Vol. 6. - P. 107-134. DOI: https://doi.org/10.1016/b978-0-12-803581-8.09304-8.

32. What is the Predictive Value of MRI for the Occurrence of Knee Replacement Surgery in Knee Osteoarthritis? / J. Pelletier [et al.] // Annals of the Rheumatic Diseases. - 2017. - Vol. 72, № 10. - P. 1594 1604. DOI: https://doi.org/10.1136/annrheumdis-2013203631.

\section{REFERENCES}

1. Krylov P.A., Baydova K.V., Emelyanov N.V., et al. Morfologiya sustavnogo khryashcha pri eksperimental'nom osteoartroze pri korrektsii sostava sinovialnoy zhidkosti surfaktant-assotsiirovannymi belkami [Articular Cartilage Morphology in Experimental Osteoarthritis with and Without Modification of Synovial Fluid by Surfactant-Associated Proteins]. Zhurnal klinicheskoy $i$ eksperimentalnoy morfologii [Journal of Clinical and Experimental Morphology], 2017, vol. 3 , no. 23 , pp. 50-55.

2. Krylov P.A., Nesmeyanova E.N., TerpilovskiyA.A., et al. Morfologiya tibiofemoralnogo sustava krysy pri eksperimentalnom osteoartroze: 3D-rekonstruktsiya na osnove tekhniki vysokotochnogo soshlifovyvaniya [Morphology of Tibiofemoral Joint in Rats with Experimental Osteoarthritis: 3D-reconstruction, Based on the Technology of High-Precision Grinding]. Zurnal anatomii $i$ gistopatologii [Journal of Anatomy and Histopathology], 2017, vol. 6, no. 3, pp. 44-49.

3. Krylov P.A., Astakhov A.S., Nesmeyanova E.N., et al. Otsenka effektivnosti issledovaniya logochnogo surfaktanta pri eksperimentalnom osteoartroze kolennogo sustava u krys: analiz 3Drekonstruktsiy [Assessment Effectiveness of Lubricant Based on Pulmonary Surfactant in
Experimental Osteoarthritis of the Knee in Rats: Analysis of 3D-Reconstructions]. Byulleten eksperimentalnoy biologii $i$ meditsiny [Bulletin of Experimental Biology and Medicine], 2019, vol. 168, no. 9, pp. 343-346.

4. Zhang Y., Wang F., Tan H., et al. Analysis of the Mineral Composition of the Human Calcified Cartilage Zone. Internet Journal of Medical Sciences, 2012, vol. 9, no. 5, pp. 353-360.

5. Phull A.-R. Eo S.-H., Abbas Q., et al. Applications of Chondrocyte-Based Cartilage Engineering: An Overview. BioMed Research International, 2016, no. 1879837, pp. 17.

6. A. Athanasiou (ed.) Articular Cartilage. Boca Raton, CRC Press Publ., 2017.696 p.

7. Camarero-Espinosa S., Rothen-Rutishauser B., Foster E. J., et al. Articular Cartilage: from Formation to Tissue Engineering. Biomaterials Science, 2016, vol. 4, no. 5, pp. 734-767. DOI: https://doi.org/10.1039/ c6bm00068a.

8. Li Y. S., Zhang F. J., Zeng C., et al. Autophagy in Osteoarthritis. Joint Bone Spine Volume, 2016, vol. 83, no. 2, pp. 143-148. DOI: https://doi.org/0.1080/ 03008207.2016.1240790.

9. Cheng N-T., Meng H., Ma L-F. Role of Autophagy in the Progression of Osteoarthritis: The Autophagy Inhibitor, 3-Methyladenine, Aggravates the Severity of Experimental Osteoarthritis. International Journal of Molecular Medicine, 2017, vol. 39, no. 5, pp. 1224-1232. DOI: https://doi.org/ 10.3892/ijmm.2017.2934.

10. Yu F.-F., Lin X.-L., Wang X., et al. Comparison of Apoptosis and Autophagy in Human Chondrocytes Induced by the T-2 and HT-2 Toxins. Toxins (Basel), 2019, vol. 11, no. 5, pp. 260. DOI: https://doi.org/ 10.3390/toxins 11050260 .

11. Emmanuel L., Ganesh N., Lakshmi S. Animal Models of Osteoarthritis: Classification, Update, and Measurement of Outcomes. Journal of Orthopaedic Surgery and Research, 2016, vol. 11. DOI: https:// doi.org/10.1186/s13018-016-0346-5.

12. Hwang H., Kim H. Chondrocyte Apoptosis in the Pathogenesis of Osteoarthritis. International Journal of Molecular Sciences, 2015, vol. 16, no. 11, pp. 26035-26054. DOI: https://doi.org/10.3390/ ijms161125943.

13. Charlier E., Relic B., Deroyer C., et al. Insights on Molecular Mechanisms of Chondrocytes Death in Osteoarthritis. International Journal of Molecular Sciences, 2016, vol. 17, no. 12. DOI: https://doi.org/ 10.3390/ijms17122146.

14. Jahn S., Seror J., Klein J. Lubrication of Articular Cartilage. Annual Review of Biomedical Engineering, 2016, vol. 18, no. 1, pp. 235-258. DOI: https://doi.org/10.1146/annurev-bioeng-081514123305. 
15. Johnson V. L., Hunter D. J. The Epidemiology of Osteoarthritis. Best Practice \& Research Clinical Rheumatology, 2014, vol. 28, no. 1, pp. 5-15. DOI: https://doi.org/10.1016/j.berh.2014.01.004.

16. Kraan P.M., Berg W.B. Chondrocyte Hypertrophy and Osteoarthritis: Role in Initiation and Progression of Cartilage Degeneration? Osteoarthritis and Cartilage, 2012, vol. 20, no. 3, pp. 223-232.1. DOI: https://doi.org/10.1016/j.joca.2011.12.003.

17. Krylov, P.A. The Grouping of Chondrocyte Receptors According to Their Control Over Cartilage Tissue Remodeling. European Journal of Molecular Biotechnology, 2014, vol. 1, no. 3, pp. 4-10. DOI: https:// doi.org/10.13187/ejmb.2014.3.4.

18. Loeser R.F., Collins J.A., Diekman B.O. Ageing and the Pathogenesis of Osteoarthritis. Nature Reviews Rheumatology, 2016, vol. 12, no. 7.pp. 412-420. DOI: https://doi.org/10.1038/nrrheum.2016.65.

19. McCulloch K., Litherland G.J., Rai T.S. Cellular Senescence in Osteoarthritis Pathology. Aging Cell, 2017, vol. 16, no. 2, pp. 210-218. DOI: https:// doi.org/10.1111/acel.12562.

20. Glyn-Jones S., Palmer A. J., Agricola R., et al. Osteoarthritis. The Lancet, 2015, vol. 386, no. 9991, pp. 376-387. DOI: https://doi.org/10.1016/S01406736(14)60802-3.

21. Veronese N., Cereda E., Maggi S., et al. Osteoarthritis and Mortality: a Prospective Cohort Study and Systematic Review with Meta Analysis. Seminars in Arthritis and Rheumatism, 2016, vol. 46, no. 2, pp. 160-167. DOI: https://doi.org/10.1016/ j.semarthrit.2016.04.002.

22. Guilak F., Nims R., Meulenbelt I. et al. Osteoarthritis as a Disease of the Cartilage Pericellular Matrix. Matrix Biology: Journal of the International Society for Matrix Biology, 2018, vol. 71-72, pp. 40-50. DOI: https://doi.org/10.1016/j.matbio.2018.05.008.

23. Pritzker K., Gay S., Jimenez S. A. et al. Osteoarthritis Cartilage Histopathology: Grading and Staging. OsteoArthritis Research Society International, 2005, vol. 14, no. 1, pp. 13-29. DOI: https://doi.org/10.1016/j.joca.2005.07.014.

24. Xia B., Di C., Zhang J., et al. Osteoarthritis Pathogenesis: A Review of Molecular Mechanisms. Calcified Tissue International, 2016, vol. 95, no. 6, pp. 495-505. DOI: https://doi.org/10.1007/s00223-0149917-9.

25. Chen D. Shen J., Zhao W., et al. Osteoarthritis: Toward a Comprehensive Understanding of Pathological Mechanism. Bone Research, 2017, vol. 5, no. 16044, DOI: https://doi.org/10.1038/boneres.2016.44.

26. Rebekah S. Articular Cartilage and Joint Development from Embryogenesis to Adulthood. Seminars in Cell \& Developmental Biology, 2017, vol. 62, pp. 50-56. DOI: https://doi.org/10.1016/ j.semcdb.2016.10.005.

27. Palazzo C., Nguyen C., Lefevre-Colau M. M., et al. Risk Factors and Burden of Osteoarthritis. Annals of Physical and Rehabilitation Medicine, 2016, vol. 59, no. 3, pp. 134-138. DOI: https://doi.org/10.1016/ j.rehab.2016.01.006.

28. Sellam J., Berenbaum F. Is Osteoarthritis a Metabolic Disease? Joint Bone Spine, 2013, vol. 80, no. 6, pp. 568-573. DOI: https://doi.org/10.1016/ j.jbspin.2013.09.007.

29. Simon T.M., Jackson D.W. Articular Cartilage: Injury Pathways and Treatment Options. Sports Medicine and Arthroscopy Review, 2018, vol. 26, no. 1, pp. 31-39. DOI: https://doi.org/10.1097/ JSA.0000000000000182.

30. Kerkman P.F., Kempers A.C., Oosterhout M., et al. Synovial Fluid Mononuclear Cells Provide an Environment for Long-Term Survival of AntibodySecreting Cells and Promote the Spontaneous Production of Anti-Citrullinated Protein Antibodies. Annals of the Rheumatic Diseases, 2016, vol. 75, no. 15, pp. 2201-2207. DOI: https://doi.org/10.1136/ annrheumdis-2015-208554.

31. Raleigh A. R., McCarty W. J., Chen A. C. et al. Synovial Joints: Mechanobiology and Tissue Engineering of Articular Cartilage and Synovial Fluid. Comprehensive Biomaterials, 2017, vol. 6, pp. 107134. DOI: https://doi.org/10.1016/b978-0-12-8035818.09304-8.

32. Pelletier J. P., Cooper C., Peterfy C., et al. What is the Predictive Value of MRI for the Occurrence of Knee Replacement Surgery in Knee Osteoarthritis? Annals of the Rheumatic Diseases, 2017, vol. 72, no. 10, pp. 1594-1604. DOI: https://doi.org/10.1136/ annrheumdis-2013-203631. 
Е.А. Близнюкова, П.А. Крылов. Феномен гиперклеточности при остеоартрозе

\section{Information About the Authors}

Ekaterina A. Bliznyukova, Student, Department of Bioengineering and Bioinformatics, Volgograd State University, Prosp. Universitetsky, 100, 400062 Volgograd, Russian Federation, div-katerina98@mail.ru.

Pavel A. Krylov, Candidate of Sciences (Biology), Associate Professor, Department of Bioengineering and Bioinformatics, Volgograd State University, Prosp. Universitetsky, 100, 400062 Volgograd, Russian Federation, krylov.pavel@volsu.ru.

\section{Информация об авторах}

Екатерина Александровна Близнюкова, студентка кафедры биоинженерии и биоинформатики, Волгоградский государственный университет, просп. Университетский, 100, 400062 г. Волгоград, Российская Федерация, div-katerina98@mail.ru.

Павел Андреевич Крылов, кандидат биологических наук, доцент кафедры биоинженерии и биоинформатики, Волгоградский государственный университет, просп. Университетский, 100, 400062 г. Волгоград, Российская Федерация, krylov.pavel@volsu.ru. 